\title{
The Sexuality of Spinal Cord Injured Women: Physiology and Pathophysiology. A Review
}

\author{
E. J. J. Bérard, MD
}

Spinal Cord Injury Unit, Rehabilitation Service, Hôpital R. Sabran, F-83406 Giens, France.

\section{Summary}

After a review of the literature concerning sexuality in spinal cord injured women, the authors studied the female paraplegic sexual responses, dependent on the different levels of injury, above thoracic 10; between thoracic 10 and thoracic 12; and distal to thoracic 12.

Allowing for specific sexual differences, genito-sexual innervation appears to be analogous in males and in females.

Sexual behaviour is, above all, determined by several neuro-psychological reactions.

Pregnancy and delivery are also discussed according to the different levels of spinal cord injury. It is noted that the paraplegic mother and the fetus are exposed to additional risks during pregnancy. During delivery, two problems are considered, autonomous dysreflexia and caesarean section.

Key words: Spinal cord injury; Female sexual aspects; Pregnancy; Delivery.

A survey of the literature published in French, English and German concerning sexuality in spinal cord injured patients, shows that females receive far less attention than do males.

The earliest authors Bors (1965), Comarr (1970) and Guttmann (1971) reported their experience and findings relating to all aspects of male sexuality, including the physiopathological basis of the treatment of anejaculation. The same authors did discuss some sexual aspects of female paraplegic patients, concentrating mainly upon the reproductive aspects, the initial amenorrhoea, pregnancy and childbirth.

To our knowledge, the first paper published on this topic was by Gerstmann in 1925, concerning the innervation of genital organs in a paraplegic woman with a neurological level at lumbar 1. A recent paper of Francois and Maury (1987) discusses some aspects of the physiology and pathophysiology of female paraplegic patients, but is limited to a few details regarding the technical prob- 
lems of sexual intercourse, and the innervation of the genital organs according to the level of the spinal cord injury, in the context of pregnancy and of delivery.

Turk et al. (1983), in the Annual Scientific Meeting of the International Society of Paraplegia in Athens in 1982, presented a paper summarising these previously mentioned aspects and included the following surprising phrase: 'During sexual intercourse, the woman is the more "passive" partner of the two, and she is receiving while the man is giving, so it is logical to conclude that the act does not affect women as much as it does men.' However, Lowe and Carole (1985) showed that there was no real decrease in emotional drive following spinal cord injury whether in male or in female patients. Prudhomme (1965) emphasised the necessity to differentiate between reproductive and sexual behaviour, and put forward the concept of the para-orgasm based, among other features, on stimulation of the secondary erogenous zones. There can be a return to, or the acquisition of, sexual identity despite the change which was described by Voillemin (1984), as 'the impossibility of achieving normal vagino-uterine orgasm due to the lack of sensation of the vagina and clitoris'.

Gillian and Brindley (1979) studied sexual reactions in the pelvic floor which are of little use in the study of spinal cord injured women. In contrast Masters and Johnson's classification of the various phases of female sexual response were used as our reference when describing the response of the female paraplegic. But we were unable to find any significant information relevant to paraplegic females in the second book by Masters and Johnson 'Human Sexual Inadequacy' (1970).

Sidman (1977) alludes to the work of Kaplan, showing the respective parts of the sympathetic and parasympathic nervous systems involved in human sexual responses (lubrication and swelling of the genitalia).

Rouffet-Tissot et al. (1978) presented a very well documented work concerning 21 deliveries in 15 patients who had sustained spinal injuries. Five caesarean sections were reported, 3 for obstetrical reasons, 1 because of a difficult labour in a paraplegic with a level at lumbar 3, and 1 for autonomic hyperreflexia in a paraplegic with a thoracic 4 level. The same author (1981) reviewed several aspects of the genito-sexual problems specific to female paraplegics, and raised the question of difficulties of intercourse due to lack of sensation, urinary incontinence and contractures. Mrs Rouffet-Tissot also discussed pregnancy and childbirth according to the different neurological levels of injury.

Young et al. (1983) presented 4 patients with pregnancies, in three spinal cord injured women, underlining pre-partum complications and autonomic hyperreflexic responses to labour.

The most practical information that we have found concerning sexual reactions in female paraplegics was in an American book by Elle Friedman-Becker (1977) entitled 'Female Sexuality Following Spinal Cord Injury'.

In a work by Thévenot (1983) the reflection on sexual behaviour led him to consider that it involved relationship, eroticism and procreation.

As previously stated above, the term 'procreation' has been evaluated in several comprehensive papers concerning spinal cord injury, including fertility, contraception, pregnancy and delivery. It is our intention to use these references and others to clarify our proposition regarding procreation in spinal cord injured women and this will in addition be illustrated with personal experiences of such 
patients. However the most important features of the present study concerns relationships and eroticism, that is physical and psychological responses related to sexuality in spinal cord injured women. The main part of our work will consist of a report of the results of both interviews, one concerning our patients, and one carried out by Friedman-Becker (1977).

\section{Material and methods}

The interviews by Friedman-Becker are very rich in details concerning the feelings and the psychological adjustments of spinal cord injured women, but we cannot use every case as a rule to understand physical response because many neurological features are missing.

Our study concerns 15 spinal cord injured women whom we interviewed personally, guided by the same questionnaire that we submitted to 10 female trainee nurses. For each patient, we first noted the spinal cord level of the injury, then if the injury was complete or incomplete, and if there was partial sensitivity below the level of injury. Questions included:

Were there still pleasant feelings in the paralysed part of the body, particularly in relation to sexual intercourse or to masturbation?

Were these feelings associated with lubrication and/or other physical responses such as swelling of the genitalia?

Was orgasm still present?

What was the content of the patient's dreams, and of their fantasies accompanying sexual intercourse?

Was there return of normal menstruation or did amenorrhoea persist?

Facts concerning the fear of or the desire to be pregnant, and the use of contraceptive methods.

What was the previous experience of pregnancy, delivery, and the postpartum period before and/or after spinal cord injury?

What problems of intimacy and privacy were present in relation to care and rehabilitation?

How attractive did patients remain after their injury?

Was there any spasticity, and if so, how did it affect the activities of the patient's daily life?

Were there problems concerning motility?

Did the patients have real continence of urine and of bowel functions?

The 15 women interviewed were well known to us, because they had received their care and rehabilitation in our Spinal Cord Unit. We therefore had access to their medical records, and to complementary information regarding their neurological syndromes and to their genito-sexual response to intimate washing or antisepsis of the genitalia.

The mean age of the patients was 32.6 years ranging from 20-55 years.

The neurological syndromes were: 3 cervical ( 2 incomplete); 3 upper thoracic (above thoracic 6); 2 mid-thoracic (thoracic 6 to thoracic 10); 3 thoracic 11 to thoracic $12 ; 4$ distal to lumbar 4 ( 1 incomplete). Ten of the patients had reflexes; 5 were flaccid.

Lifestyle of the patients: 9 were living with a male person ( 6 of these patients were married to that person); 6 lived alone or with their parents. 
Amenorrhoea: 0 to 9 cycles (the mean was 4 cycles).

Sexual experience prior to their spinal injury: 12 out of 15 .

Sexual experience following their injury: 10 out of 15 .

Contraception: 5 of the patients took oral contraceptives; 2 had an intra-uterine device (i.e. 7 out of 15 had some form of contraception).

Pregnancies: 14 had pregnancies ( 2 abortions, 1 was paraplegic from thoracic 6 , and 1 paraplegic from lumbar 2 level).

Deliveries: 12 (1 patient with a thoracic 3 level required forceps and episiotomy; 2 with a thoracic 10 level required caesarian section; 3 with their level at thoracic 11 had a natural birth but required an episiotomy; 2 with a lumbar 1 lesion and flaccidity, required a caesarian section; 1 with a L4 level lesion had a natural birth but required an episiotomy; 3 with a level at $S 1$ had a natural birth).

There was a comparison with a sample of 10 trainee female nurses, considering attractiveness, sexual fulfilment and how they described orgasm, contraception and conception. Two of these nurses had urinary disturbances.

\section{The sexual responses of spinal cord injured women}

We feel it best to begin by considering the physiological reactions of non-paraplegic females, as were described by Masters and Johnson (1965). That is, the resting state, an excitation phase, a plateau phase, orgasm, and a relaxation phase.

\section{The resting state}

In spinal cord injured women this may be characterised by insensitivity in the genital area, voluntary motor deficit and disturbance of perineal reflexes. There is total loss of sensitivity of the internal organs in patients with complete transection of the spinal cord above thoracic 10 level, and only partial insensitivity when there is injury in addition to fracture at thoracic 12-lumbar 1, with lesions of the spinal cord below thoracic 12 . This partial sensitivity is paradoxically accompanied by loss of sensation of the external genitalia. Loss of such sensation occurs as far distal as sacral 2 , beyond this there may be some sensation. Total sensitivity in this area is recovered when all of the S2-S5 spinal cord is intact and is connected to conscious perception. Female paraplegics who must have had complete loss of external genital sensation, did report the presence of precise sensations in this area, but close questioning revealed that these were urethral sensations transmitted to the external genitalia. Voluntary motor power of the pelvic floor is maintained only in some patients with incomplete lesions with the S2-S5 region of the spinal cord partially intact, and under partial voluntary control. Spasticity of the muscles of the pelvic floor, and of the levator ani can be demonstrated, and especially of the constrictor vulvae during anal or clitoral stimulation. Such spasticity is the result of an incomplete spinal cord lesion or in those with complete injuries some distance from the conus medullaris and the cauda equina. These data on sensitivity, voluntary motor power and perineal reflexes can be used to establish the innervation network in this area (Fig. 1). The following phases of sexual response in the 


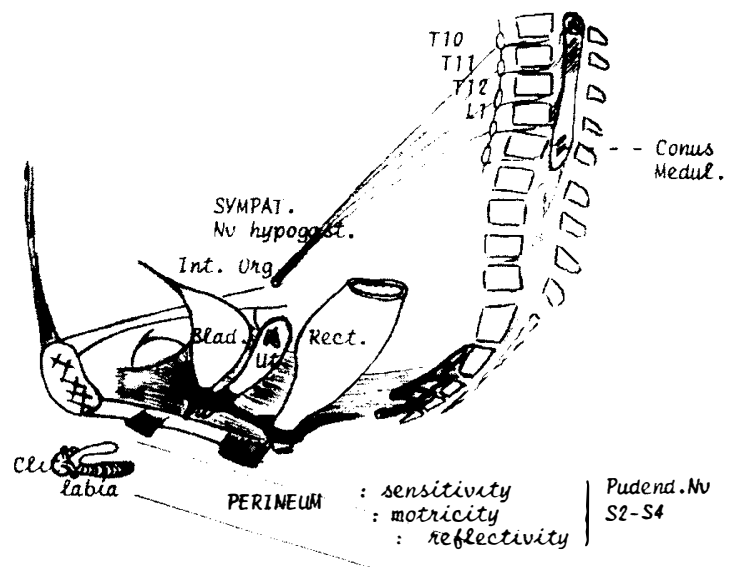

Figure 1 Female genital innervation.

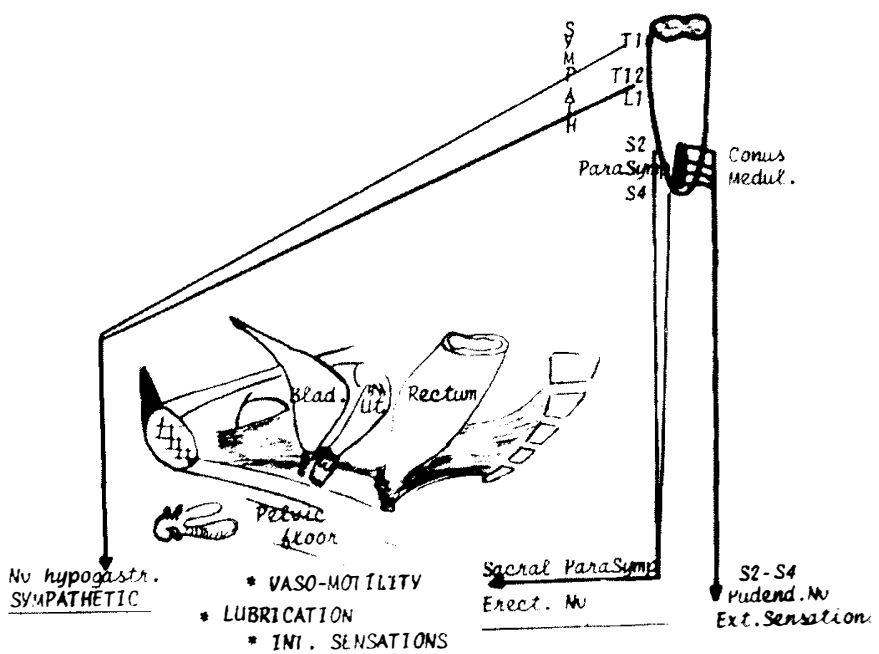

Figure 2 Female sexual response and the autonomous nervous system.

female paraplegic enables us to understand the complementary autonomic system (Fig. 2).

\section{The excitation phase}

This corresponds to vaginal lubrication, swelling of the clitoral gland and congestion of the labia (such phenomena of secretion and vasodilation are usually due to the parasympathetic nervous system). A notable effect during this phase is also that of the 'build-up of tension' of warmth in the region of the genitalia, a feeling which is not superficial, and is perceived rather more deeply by females. Lubrication may still occur, with its psychogenic and reflex components at all levels in those with incomplete spinal cord injuries. There is absence of lubrication, either reflex or psychogenic when the injury is situated between T10 and 
T12. A remaining psychogenic lubrication below $\mathrm{T} 12$ indicates involvement of the sympathetic nervous system in this response. In those with high complete lesions, far from the conus medullaris, at thoracic 9 level and above, reflex lubrication only may occur. In those with injuries below thoracic 12, psychogenic lubrication is present. Congestion of the external genitalia may be observed in female paraplegics with injuries above T10, this is reflex congestion in response to, for example, washing the genitals before catheterisation (in the same way as a reflex erection may occur in males under the same circumstances). This reflex congestion is also observed in female paraplegics with incomplete spinal cord injury, in whom psychogenic stimulation may also be expected. Female paraplegics with complete lesions above thoracic 10 can perceive sensations which accompany the excitation phase, these feelings are not the same as those experienced prior to spinal cord injury and are like the feeling of a full bladder or to a burning feeling in the urethra. There is no sensation during the excitation phase in those with spinal cord lesions between T10 and T12. Sensation is present but is very much attenuated when the injury is below T12.

\section{The plateau phase}

This phase is characterised by local clitoridal retraction and is perceived by the woman as a heightening of tension in the genital area. In those with complete transection of the spinal cord above T10, masturbation may provoke such a retraction of the external genitalia, but this was not reported by women with injuries below this level. This remains to be verified. Confirmation of this observation could indicate that the sacral parasympathetic system is involved in the morphological changes in the external genitalia during the plateau phase. In those with complete spinal cord injuries above T6, and with cervical spinal cord injury, the plateau phase is perceived in the same way as the phenomena of autonomic hyperreflexia, with headaches, oppression and bradycardia. There is complete loss of sensation when the lesion is between T10 and T12. Sensation during the plateau phase exists where there is a lesion below T12, but it is very attenuated.

\section{Orgasm}

In patients with high complete lesions, orgasm can be summarised as a series of noisy manifestations of hyperreflexia (severe hypertension) followed by complete relaxation with, in those who are spastic, complete disappearance of muscle spasticity (as in the case of tetraplegic males after ejaculation) (Frankel and Mathias, 1980). A paraplegic woman with a complete lesion at T3 in our series reported that she did not wish to obtain this point any more because of discomfort and of fear. Sensation is absent in paraplegic women with injuries between $\mathrm{T} 10$ and $\mathrm{T} 12$. If their injury is below $\mathrm{T} 12$, there is deadened sensation which tends to cause frustration-'I can go so far and no further'. Pleasure may be heightened or compensated for by concomitant stimulation of either an erogenous zone above the level of the injury, or the dysaesthetic band at the level of injury. Some female paraplegic patients are in fact capable of deep mental concentration fixed on their genital organs during intercourse and in whom 
erogenous stimulation above the level of the lesion can provoke paroxysmal pleasure, feel that it originated in the genitalia. It is felt that this is due to mental displacement of a feeling, and is not a psychophysiological process incorporating autonomic genital phenomena as is the case with true orgasm.

\section{The relaxation phase}

This phase follows the orgasm in the sequence of congestive reactions, so that an orgasm not followed by a relaxation phase has no physiological significance in the context of normal sexual reactions in the female. It would appear to be important in the future, to stress this point with female paraplegics who experience the first three phases of sexual response during intercourse or masturbation, that is that they might observe, just after orgasm, if there is a coexistent congestive response of the external genitalia.

\section{Psychological activity accompanying sexual reactions}

Regarding our sample of non-paraplegic women, the psychological activity which accompanies sexual response enables the female paraplegic (also) to regain her sexual identity. Sexual pleasure may start in the spinal cord or elsewhere, but it is experienced 'in the head'. Numerous women use this to cope with their deafferentation by creating a new pleasure-a fantasy association, which they use like an orgasm in the sense that it is the pleasure that concludes sexual intercourse. The fantasy itself is considered to be extremely important, both by paraplegic and non-paraplegic women. Amongst the spinal cord injured women interviewed by both Friedman-Becker and ourselves, there was a total correlation between the richness of the fantasy and the fulfillment of their sexual life. In contrast, all women who had abandoned their sexuality, no longer indulging in fantasies, were the ones who were unable to come to terms with their handicap. Even amongst tetraplegic women, who often had insuperable difficulties in having intercourse, the fantasy represented a way of achieving a certain adjustment. It is interesting to note that most of the spinal cord injured women in our series dreamt about erotic scenes with their able body, even those who had had no sexual intercourse since their injury. This means that the subconscious is of great importance in coping with the sexuality of handicapped people.

\section{Problems connected with sexual intercourse}

\section{Spasticity and contractures}

When the adductor muscles are involved, it can be difficult for the partners to get close together, the same may occur with certain orthopaedic problems where there is limitation of hip movements (including para-articular ossification, with ankylosis, or contractures of the hip flexors). Such difficulties were experienced by two non-paraplegic women in our sample, who had orthopaedic problems only. Spasticity of the pelvic floor can also adversely affect intravaginal penetra- 
tion, to which is added secondary psychogenic impotence on the part of the partner.

\section{Lubrication problems}

Lubrication problems can also hinder or prevent penetration and the couple must be informed beforehand of the paraplegic woman's response in accordance with the neurological status. When lubrication will respond to a reflex mechanism, it is particularly important to explain the techniques of triggering the physiological reflex sexual responses which greatly help penetration and intercourse. In those with spinal injury lacking autonomic pathways, neither psychogenic nor reflex lubrication can be induced. In such instances the systematic use of lubricating jellies is to be recommended.

\section{Problems of bladder and bowel incontinence}

When these are due to reflex contraction or increased pressure, these problems have in all instances a catastrophic psychological effect both for the woman and her partner. We therefore recommend that female paraplegics should carry out a regular routine of intestinal voiding and should also check rectal vacuity if there is any doubt, before sexual intercourse, irrespective of whether they have a reflex or a flaccid syndrome. If the woman is not perfectly certain of the completeness of micturition, urinary incontinence can be prevented by self-catheterisation of the bladder for safety, just prior to intercourse. One young nonparaplegic woman in our series also had such problems of bladder incontinence during intercourse which obliged her to void completely just prior to intercourse. Women with an indwelling urinary catheter are not obliged to remove it before intercourse, but they must be very careful to lubricate it in order to prevent problems of friction during intercourse. Other women prefer to remove their catheters for aesthetic reasons, and then to replace them afterwards.

\section{The risk of urinary tract infections}

The risk of urinary tract infections of perineal origin is increased by intercourse, but it is in poorly rehabilitated women who incompletely void their bladders who are at greater risk, in addition to those who do not observe an adequate hygiene routine. But practising intermittent self-catheterisation for a temporary period can resolve the problem in paraplegic women.

\section{Fertility}

Amenorrhoea occurs in all female patients after traumatic spinal cord injury, and Rouffet-Tissot (Maury, 1981) established the duration of amenorrhoea to be between 3 and 9 months. A very complete study has been done on the occurrence of amenorrhoea in spinal cord injury patients by Axel (1982). Our experience shows that the period of amenorrhoea is shorter, 4 cycles on the average. Blood luteinising hormone and follicular stimulating hormone levels 
are usually monitored, but they vary greatly and are as variable as they are in males (Leriche, 1976). Female paraplegics can expect to return home for the first time between 3 and 4 months following the accident, which we consider to be the period when the normal menstrual cycle becomes re-established. Women are in an anovulatory phase during the initial amenorrhoea, and it is in this phase that there is a very high risk of unpredictable ovulation before the first menstruation occurs. We therefore recommend either regular monitoring of fertility based on observation of the cervical mucus (Billings, 1981) or that precautions are taken by the partner, particularly in cases where pregnancy is strictly contra-indicated. During this period, the prescription of oral contraceptives is not recommended because of added risks. The problem inherent in the use of an intra-uterine device (IUD) remains, to which are added those of the spinal cord injury (insensitivity and genito-urinary tract infection). Once the couple has been sufficiently informed about all contraceptive measures and their respective risks, we feel that it is not for us to recommend which method of contraception is used, this decision should belong to the couple.

\section{Pregnancy}

We have referred both to our clinical experience, and papers that have been recently published which give clinical experience as well as much valuable practical advice for spinal cord injured women. (Rouffet-Tissot, 1978, 1981; Tsoutsolapides, 1982; Greenspoon and Paul, 1986; Verduyn et al., 1986).

Notwithstanding the problems specific to the female paraplegic, a normal pregnancy lasts $40-44$ weeks. Frequent examinations should therefore be planned from week 32 onwards, and some doctors even recommend permanent observation in an obstetrical department as early as the end of week 34, particularly in those with injuries above T12 (Letcher and Goldfine, 1986). Rossier et al. (1969) pointed out the specific problems connected with pregnancy and labour in high spinal cord injured women.

According to specialists in peridural anaesthesia, uterine innervation arises from T10, T11 and T12 levels of the spinal cord (Fig. 3), in spite of Gertsmann's publication of a 27-year-old woman who led him to believe that uterine innervation was located between L5 and S5 (Gertsmann, 1926). Generally in patients with a complete lesion ahove T10, neither contractions nor the movements of the fetus are felt (Rouffet-Tissot, 1978, 1981) but one female paraplegic patient with a complete spinal cord lesion at $\mathrm{T} 3$, and another patient with a complete injury below $\mathrm{C} 7$ assured us that they had both felt movements and contractions in the form of minor episodes of autonomous hyperreflexia. Those with lesions below T12 do feel their uterine contractions and fetal movements normally.

The effect of pregnancy upon the problems inherent in spinal cord injury include the following: 


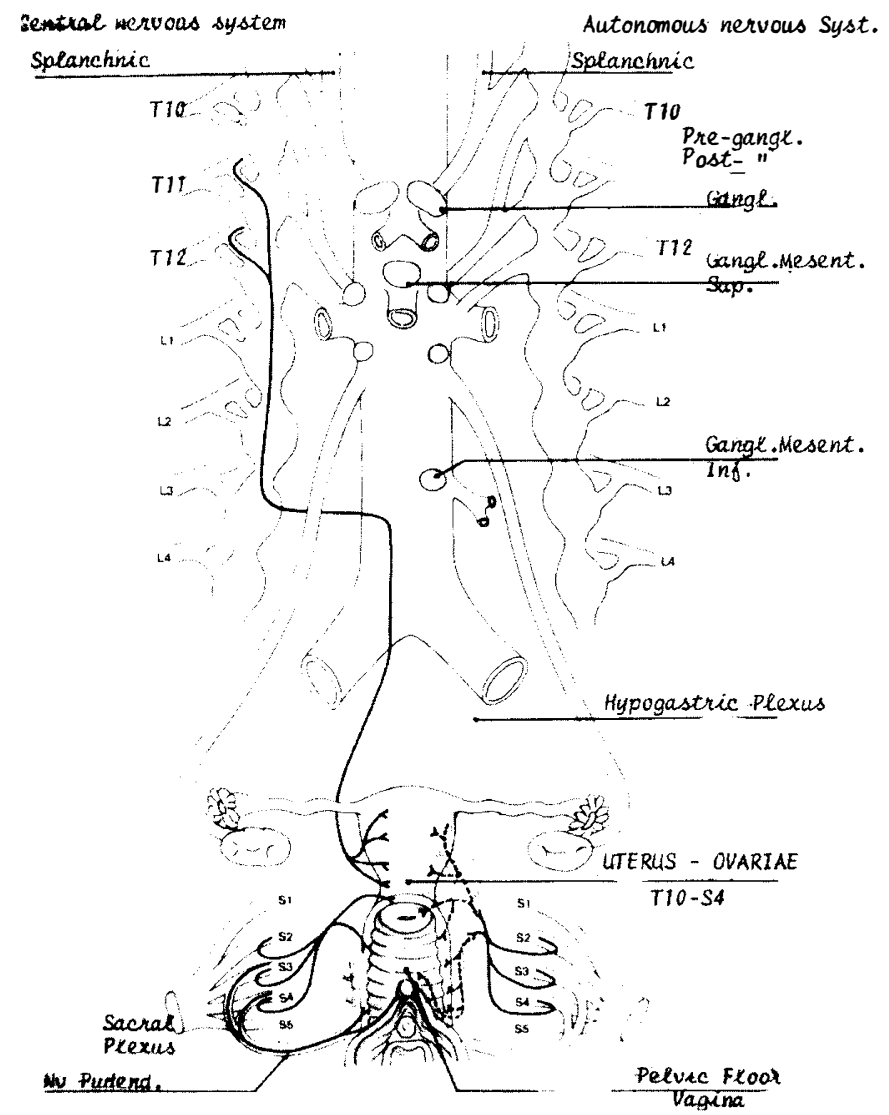

Figure 3 Female genital organs anaesthetic levels. From L. Lecron and A. M. Le Mat in Anesthesie-Reanimation-Nutrition Lab. Roger Bellon Ed. Neuilly.

\section{Urinary tract infections}

These are already a major problem for non-paraplegic females as they may provoke hypotrophy, premature delivery and fetal death. In paraplegic women infection is even more important and should be prevented. Maintenance of a 24 hour urine volume in excess of 2 litres, and intermittent self-catheterisation are necessary for greater security. Systematic monitoring of leukocyturia by reagent strips is very reliable due to the absence of false negative results. In cases of doubt, bacteriological examination of the urine is carried out and the patient's infection is treated. Sulphonamides and tetracyclines are contraindicated.

\section{The risk of constipation}

This is also increased and should be prevented by an appropriate diet, a sufficient quantity of liquids, mild laxatives and stool softeners. 


\section{The blood picture}

The blood picture may be affected. There is a higher thrombogenic risk which contraindicates prolonged periods in bed if no special precautions are taken.

\section{Osteoporosis}

From the work of Minaire and Berard (1979) on immobilisation induced osteoporosis, a reduction in the bone mineral content is expected and we recommend a calcium-rich diet during pregnancy.

\section{Effects of the spinal cord injury upon the pregnancy}

In 1981, we contributed a chapter on this subject (Berard and Thoulon in Minaire, Paraplegia and Tetraplegia). In a more recent publication (Verduyn et al., 1986), there are data which confirm the need for strict supervision during pregnancy. These authors also stress the need for various forms of aids during delivery, such as caesarian section, the prevention of autonomous hyperreflexia, the use of forceps. On this subject, Rouffet-Tissot (1978) reports a complementary experience concerning caesarian section.

A paraplegic pregnancy is therefore a high risk pregnancy, with a risk of increasing the maternal complications (which we have analysed) and risks for the child. Supervision involves the usual parameters monitored by obstetricians during routine visits throughout, and particularly those towards the end of the pregnancy.

Albuminuria. The risk of toxemia pregnancy is greater if there has been repeated urinary tract infection and residual albuminuria.

Blood pressure although it may be normal between two attacks of hyperreflexia, is dangerous for the fetus and should be prevented by using Pentholinium, alpha-blockers, or calcium-antagonists (Lindan et al., 1985). In the case of a high risk of abortion, epidural analgesia is proposed as an early procedure. Ravindran et al. (1981) reported the case of the evacuation of a dead fetus of 20 weeks gestation due to an attack of autonomic hyperreflexia in the mother. High risks of premature delivery could be prevented by beta-mimetics (Ritodrine Hydrochloride) as published by Letcher (1986) in a patient with paraplegia at T7 level, a 27-year-old woman who was 30 weeks pregnant.

Lower limb oedema presents a higher risk for the female paraplegic than the male, and it appears prudent to recommend that such patients should wear support stockings systematically, and to have their legs elevated several times a day.

Gynaecological/obstetrical examinations are carried out every 2 weeks after the 32nd week; in particular the uterine height and maternal weight gain.

Laboratory tests require to be performed at the least suspicion of a problem, to monitor fetal and placental vitality (urinary oestriol and plasma adrenocortical hormone levels).

The measurement of thoracic and biparietal diameters by fetal echography enables fetal growth rate to be determined, the value of which increases as the pregnancy approaches term. 


\section{Delivery}

It is important to differentiate between three groups of female paraplegic patients:

\section{Those with injuries above T10.}

$A$ priori uterine contractions are effective although they are not directly felt by the patient. Labour progresses normally but there is a risk of autonomous hyperreflexia if the injury is above T6 and if previous episodes of paroxysmal hypertension have occurred. We used to recommend the administration of Pentholinium for several days before childbirth (Berard and Thoulon, 1982). Currently, having witnessed an extremely serious case where there was hyperreflexia during labour, and particularly at the stage of expulsion, in a patient with paraplegia at the 3rd thoracic level, we now prefer in conjunction with the obstetrician and anaesthetist, to use peridural anaesthesia systematically. This technique has been used by others particularly in the case of delivery of twins in patients with spinal cord injury in patients with a neurológical level above T6 (Watson and Downey, 1980). Verduyn (1986) reports the use of many other drugs, such as Arfonad. An effective premedication for autonomic hyperreflexia is essential whatever substance is chosen. Paralysis of the abdominal muscles usually renders ineffective the efforts to expel the fetus, and the obstetrician must be ready to use forceps and to carry out an episiotomy. Placental birth usually takes place without any problem.

\section{Spinal injuries in patients with a lesion at T10 to T11}

The uterus is apparently deprived of all reflex function which involves the spinal cord, and could theoretically be completely inert during the delivery. This is an a priori assertion which has not been confirmed by closer investigations. A peridural (epidural) anaesthesia which produces an anaesthetic level higher than the sacral spinal cord, does not produce uterine inertia (Fig. 3). Rouffet-Tissot (1978) does not report any uterine inertia at these levels. In our series a patient with a level at $\mathrm{T} 11$ had three deliveries by natural childbirth and with satisfactory APGAR scores. Doubt arises in such patients and makes the choice of a caesarian section at term mandatory. Spinal evoked potentials may give some information, but it is simpler to test for upper and lower cutaneo-abdominal reflexes and investigations of autonomic reflexia such as sweating tests.

\section{Spinal cord injuries in patients below T12}

These do not totally have loss of perception of the uterus during labour, but such patients do produce perineal insensitivity, favouring tears during the phase of expulsion, and could produce damage to the perineal musculature. Referring to two deliveries in a woman with a lesion at lumbar 2 level, Tsoutsolapides (1982) judged that the labour and the delivery were painless. 


\section{Neurological level of the injury}

Irrespective of this, paraplegic parturients should be warned of the risk of a premature delivery going unnoticed, due to the contractions not being felt and the breaking of the waters being confused with urinary incontinence. Such mistakes would be all the more serious in situations where there is a breech presentation. In paraplegic parturients, it is also essential to systematically monitor uterine contractions during labour by cutaneous tocography and fetal heart rate by ECG.

\section{Post-partum aspects}

In paraplegic women both urinary tract infections and venous thrombosis of the lower limbs constitute a higher risk than in other patients, and therefore it is essential that they should be prevented. Breast-feeding does not cause any extra problems for paraplegic women.

\section{Conclusion}

The sexuality of paraplegic women has been neglected for too long, compared with that for male paraplegic patients. There appeared to be many analogies between genito-sexual innervation in males and in females, especially concerning the autonomic nervous system. Complementary research appears to be necessary to achieve a better understanding of orgasm and of sexual pleasure in women with spinal cord injuries. Physical reinvestment and psychological adjustment must be made very early to obtain a sexual identity that can be restored in female paraplegics and tetraplegics. A large number of paraplegic and tetraplegic patients wish to have children, but only a few indulge in behaviour which could lead to actual pregnancy. Nevertheless the pregnancy must be considered as a high-risk pregnancy and treated as such. Natural childbirth remains the general rule in most cases, with peridural anaesthesia in those with spinal injuries above thoracic 6 level, to combat autonomous hyperreflexia. The post-partum period also requires increased supervision in women who have paraplegia or tetraplegia.

\section{References}

AXEL S 1982 Spinal cord injured women's concerns: menstruation and pregnancy. Rehabilitation Nursing 10:10-15.

Berard E., Thoulon JM 1982 Grossesse et Paraplégie. In: Minaire: Paraplégie et Tétraplégie Guide pratique de la Rééducation et de la Réadaptation. Paris-Masson Edit pp 213-216.

Berard E, Depassio J, PANGaud N, et al. 1985 Self catheterization: urinary complications and the social resettlement of spinal cord injured patients. Paraplegia 23:386.

BILlingS JJ 1981 Cervical mucus: The biological marker of fertility and infertility. International fournal of Fertility 26:182-195.

BORS E, COMARR AE 1960 Neurological disturbances of sexual function with special reference to 529 patients with spinal cord injury. Urol. Surv. 10:191.

Bors E 1965 Sexual function in patients with Spinal Cord Injury. In: Harris Ph.; Spinal Injuries Morrison and Gibb Ltd; London pp 70-79.

ComarR AE, VIGUE M 1978 Sexual conselling among male and female patients with spinal cord and/or Cauda equina injury. American fournal of Physical Medicine 57:107.

Francois N, MaUry M. 1987 Sexual aspects in paraplegic patients. Paraplegia 25:289-292. 
Frankel HL, Mathias CJ 1980 Severe hypertension in patients with high spinal cord lesions undergoing electro-ejaculation. Management with prostaglandin E2. Paraplegia 18:293-299.

FRIEDMAN-BECKER E 1977 Female sexuality following paraplegia. Cheever Publishing Edit Bloomington Ill.

Gillan P, BRINDLEY GS 1979 Vaginal and pelvic floor responses to sexual stimulation. Psychophysiology 16:471-481.

GERTSMANN M 1926 Über Uterusinnervation an Hand des Falles einer Geburt bei Querschnittslähmung Monatschrift f. Geburthelfe \& Gynecology 5-6:253-257.

GreEnspoon JS, PAUL RH 1986 Paraplegia and quadriplegia: special consideration during pregnancy and labor and delivery. American fournal of Obstetrics and Gynaecology 155:738-741.

GUTTMANN L 1964 The married life of paraplegics and tetraplegics. Paraplegia 2:182.

GutTMANN L 1973 Spinal cord injuries. Comprehensive management and research. Blackwell Edit. Oxford.

JOINER E, LINDAN R 1982 Experience with self-intermittent catheterisation for women with neurological dysfunctions of the bladder. Paraplegia 20:147-153.

KahN-Nathan J 1973 Le rapport sexuel. In: Encyclopédie de la vie sexuelle. De la physiologie à la psychologie. Hachette Edit Paris pp 77-87.

Leriche A, Berard E, VAuZelle JL, et al. 1977-78 Histological and hormonal testicular changes in spinal cord injured patients. Paraplegia 15:274-279.

LETCHER JC, GOLDFINE L 1986 Management of a pregnant paraplegic patient in a rehabilitation center. Archives of Physical Medicine and Rehabilitation 67:477-478.

LINDAN R, LEFFLER EJ, KEDIA KR 1985 A comparison of the efficacy of an alpha 1 adrenergic blocker in the slow calcium channel blocker in the control of autonomic dysreflexia. Paraplegia 23:34-38.

LOWE J, CARROLL D 1985 The effects of spinal injury on the intensity of emotional experience. British fournal of Clinical Psychology 24:135-136.

MAsters WH, Johnson VE 1965 Human sexual response. Little, Brown Edit. \& Co. Boston pp 65-130.

MONNET F 1987 Anesthésie et réanimation des traumatisés médullaires au stade séquellaire. Cahiers d'anesthésiologie 35:305-315.

Prudhomme H, Hamon F, Le Rebours P 1985 La sexualité du blessé médullaire: la prise en compte de soi en institution. Soins 452:3-6.

RavindRan RS, Cummins D, Smith I 1981 Experience with the use of Nitroprusside and subsequent epidural analgesia in a pregnant quadriplegic patient. Anesthesia Analgesia 60:6163.

Rossier AB, Ruffieux M, ZIEgler WH 1969 Pregnancy and labour in high traumatic spinal cord lesions. Paraplegia 7:210-216.

Rouffet-Tissot MJ, Chapelle PA, Pannier S 1978 Grossesse-Accouchement-Moyens de contraception. A propos de 15 paraplégiques ayant eu des enfants. Annales de Medécine Physique 21:451-458.

RoufFET-Tissot MJ 1982 Le fonction genito-sexuelle de la femme paraplégique. In: Maury ' $\mathrm{La}$ Paraplégie' Flammarion Edit pp 415-420.

SIDMAN JM 1977 Sexual functioning and the physically disabled adult. American fournal of Occupational Therapy 31:81-85.

Thevenot X 1983 Repères éthiques. Salvator 3rd Ed. Mulhouse.

TSOUTSOLAPIDES GC 1982 Pregnancy in paraplegia: a case report. International fournal of Gynaecology and Obstetrics 20:79-83.

Turk R, Turk M, Assejev V 1983 The female paraplegic and mother-child relations. Paraplegia 21:186-191.

VERDUYN WH 1986 Spinal cord injured women, pregnancy and delivery. Paraplegia 24:231-240.

Voillemin M 1984 Problèmes genito-sexuels du paraplegique. Rev. de l'infirmière 9:45-46.

WATSON DW, DownEY G 1980 Epidural anaesthesia for labor and delivery of twins of a paraplegic mother. Anesthesiology 52:259-261.

Young BK, Katz M, KLein S 1983 Pregnancy after spinal cord injury. Altered maternal and fetal response to labor. Obstetrics and Gynaecology 62:59-65. 